\title{
Editorial: Tropical Forest Ecosystem Responses to Increasing Nutrient Availability
}

\author{
Jürgen Homeier ${ }^{1,2 *}$, Selene Báez ${ }^{3}$, Dietrich Hertel ${ }^{1,2}$ and Christoph Leuschner ${ }^{1,2}$ \\ ${ }^{1}$ Plant Ecology and Ecosystems Research, University of Goettingen, Goettingen, Germany, ${ }^{2}$ Centre of Biodiversity and \\ Sustainable Land Use (CBL), University of Goettingen, Goettingen, Germany, ${ }^{3}$ Instituto de Ciencias Biológicas, Escuela \\ Politécnica Nacional del Ecuador, Quito, Ecuador
}

Keywords: biogeochemical cycles, global change, nitrogen, nutrient deposition, phosphorus, tree response

\section{Editorial on the Research Topic}

\section{Tropical Forest Ecosystem Responses to Increasing Nutrient Availability}

Human activity is nowadays altering the structure and functioning of ecosystems in most regions of the world. While deforestation and conversion to agricultural land are the most visible threats to tropical forests worldwide, these systems are also increasingly exposed to atmospheric nutrient deposition and climate change (Lewis et al., 2009, 2015; Malhi et al., 2014; Newbold et al., 2014). Even the most remote tropical forest areas are expected to receive rising amounts of air-borne nutrients, which will have unknown consequences for the biogeochemical cycles, structure and functioning of these systems, no matter if they are within protected areas or not (e.g., Wilcke et al., 2013; Fernández-Martínez et al., 2014). In the decades to come, both climate change and atmospheric deposition likely will amplify the pressure exerted on the remaining tropical forests. Today, effects of global warming are already recognizable in the structure and species composition of tropical forests (e.g., Duque et al., 2015; Báez et al., 2016), and the foliar N concentrations of tropical trees have been found to increase in certain regions (e.g., Hietz et al., 2011). However, the effects of increased atmospheric nutrient deposition on the biological diversity and ecosystem functioning of tropical forests are currently poorly understood. No doubt, politicians, forest managers and scientists need a mechanistic understanding of the processes of change that are triggered by continued nutrient addition, in order to sustainably manage and conserve these systems in the future.

Only in the last decade, increasing research efforts have been directed toward the understanding of the consequences of nutrient inputs for tropical ecosystems, including several replicated field experiments (e.g., Wright et al., 2011; Homeier et al., 2012). This special issue brings together the results from studies exploring the effects of experimental nutrient manipulation in tropical forests at different organization levels, ranging from single species to the ecosystem level. Six of the nine articles in the issue deal with the ongoing interdisciplinary nutrient manipulation experiment in perhumid Andean forests of southern Ecuador (NUMEX). They address a variety of topics, notably effects of $\mathrm{N}$ and/or $\mathrm{P}$ addition on soil carbon and nitrogen concentrations (Velescu et al.), soil phosphatase activity (Dietrich et al.), and soil $\mathrm{N}_{2} \mathrm{O}$ fluxes (Müller et al.) and soil aggregation (Camenzind et al.), and they deal with the response of tree seedlings to increased nutrient availability (Cárate-Tandalla et al.) and changes in the wood anatomy of a locally common tree species (Spannl et al.). The paper by Powers et al. reviews the diversity of nutrient addition effects on tropical dry forests, and Ostertag and DiManno review plant foliar responses to $\mathrm{N}$ and $\mathrm{P}$ fertilization in different ecosystems based on a literature survey. Hofhansl et al. discuss potential interactive effects of nutrient addition and increasing atmospheric $\left[\mathrm{CO}_{2}\right]$ in tropical Amazonian lowland forests as studied in the AmazonFACE and AFEX experiments. All studies report significant changes in the studied ecosystem components or processes in response to nutrient 
addition, highlighting the importance of even small alterations in the nutrient cycle of tropical forests for their functioning.

The magnitude of potential tropical forest responses to increasing nutrient availability depends on the compartment considered and the amount and duration of nutrient addition, ranging from minor alterations in biogeochemical cycles or altered growth rates to shifts in species composition, biotic homogenization and markedly altered ecosystem services. Reactions at all organization levels are likely to be modified or amplified by feedback with other disturbances and could lead to a decrease of ecosystem resilience. Eventually, long-term nutrient deposition may result in alternative stable forest states or even novel ecosystems. Because of the ecological complexity of tropical forests with different forest types and even the species within a given forest responding in different ways to nutrient addition, well-designed comprehensive studies combining manipulative approaches with long-term monitoring are needed to be able to predict the fate of these systems during the next decades.

Future studies should ideally combine the monitoring of climate, element fluxes and forest functioning with an evaluation of species composition and species performance (e.g., Zhou et al.,

\section{REFERENCES}

Báez, S., Jaramillo, L., Cuesta, F., and Donoso, D. A. (2016). Effects of climate change on Andean biodiversity: a synthesis of studies published until 2015. Neotrop. Biodivers. 2, 181-194. doi: 10.1080/23766808.2016.1248710

Duque, A., Stevenson, P. R., and Feeley, K. J. (2015). Thermophilization of adult and juvenile tree communities in the northern tropical Andes. Proc. Natl. Acad. Sci. U.S.A. 112, 10744-10749. doi: 10.1073/pnas.1506570112

Fayle, T. M., Turner, E. C., Basset, Y., Ewers, R. M., Reynolds, G., and Novotny, V. (2015). Whole-ecosystem experimental manipulations of tropical forests. Trends Ecol. Evol. 30, 334-346. doi: 10.1016/j.tree.2015.03.010

Fernández-Martínez, M., Vicca, S., Janssens, I. A., Sardans, J., Luyssaert, S., Campioli, M., et al. (2014). Nutrient availability as the key regulator of global forest carbon balance. Nat. Clim. Chang. 4, 471-476. doi: 10.1038/nclimate2177

Hietz, P., Turner, B. L., Wanek, W., Richter, A., Nock, C. A., and Wright, S. J. (2011). Long-term change in the nitrogen cycle of tropical forests. Science 334, 664-666. doi: 10.1126/science.1211979

Homeier, J., Hertel, D., Camezind, T., Cumbicus, N. L., Maraun, M., Martinson, G. O., et al., (2012). Tropical Andean Forests are highly susceptible to nutrient inputs -Rapid effects of experimental $\mathrm{N}$ and $\mathrm{P}$ addition to an Ecuadorian montane forest. PLoS ONE 7:e47128. doi: 10.1371/journal.pone.0047128

Lewis, S. L., Edwards, D. P., and Galbraith, D. (2015). Increasing human dominance of tropical forests. Science 349, 827-832. doi: 10.1126/science. aaa9932

Lewis, S. L., Lloyd, J., Sitch, S., Mitchard, E. T., and Laurance, W. F. (2009). Changing ecology of tropical forests: evidence and drivers. Annu. Rev. Ecol. Evol. Syst. 40, 529-549. doi: 10.1146/annurev.ecolsys.39.110707. 173345

Malhi, Y., Gardner, T. A., Goldsmith, G. R., Silman, M. R., and Zelazowski, P. (2014). Tropical forests in the Anthropocene. Annu. Rev. Environ. Resour. 39, 125-159. doi: 10.1146/annurev-environ-030713-155141
2013; Fayle et al., 2015; Trumbore et al., 2015; Mori et al., 2017). The recently obtained results suggest that study periods should have a minimum extension of 10 years, since climate variation and specific weather events can interfere with the effects of altered nutrient availability. Since most tropical forests are by far too diverse to study every species, we suggest focusing primarily on abundant taxa and important functional species groups. Finally, to further understand how human activities are affecting tropical forest, modeling approaches are needed that integrate the observed process responses and help understand the mechanistic relationships that drive the change.

\section{AUTHOR CONTRIBUTIONS}

JH organized the Research Topic together with SB, DH, and CL.

\section{ACKNOWLEDGMENTS}

We thank all authors for their contributions, the reviewers for valuable comments, and the Frontiers Editorial Office for improving the layout of this Research Topic.

Mori, A. S., Lertzman, K. P., and Gustafsson, L. (2017). Biodiversity and ecosystem services in forest ecosystems: a research agenda for applied forest ecology. J. Appl. Ecol. 54, 12-27. doi: 10.1111/1365-2664.12669

Newbold, T., Hudson, L. N., Phillips, H. R., Hill, S. L., Contu, S., Lysenko, I., et al. (2014). A global model of the response of tropical and sub-tropical forest biodiversity to anthropogenic pressures. Proc. R. Soc. Lond. B Biol. Sci. 281, 20141371. doi: 10.1098/rspb.2014.1371

Trumbore, S., Brando, P., and Hartmann, H. (2015). Forest health and global change. Science 349, 814-818. doi: 10.1126/science.aac6759

Wilcke, W., Leimer, S., Peters, T., Emck, P., Rollenbeck, R., Trachte, K., et al. (2013). The nitrogen cycle of tropical montane forest in Ecuador turns inorganic under environmental change. Global Biogeochem. Cycles 27, 1194-1204. doi: 10.1002/2012GB004471

Wright, S. J., Yavitt, J. B., Wurzburger, N., Turner, B. L., Tanner, E. V., Sayer, E. J., et al. (2011). Potassium, phosphorus, or nitrogen limit root allocation, tree growth, or litter production in a lowland tropical forest. Ecology 92, 1616-1625. doi: 10.1890/10-1558.1

Zhou, X., Fu, Y., Zhou, L., Li, B., and Luo, Y. (2013). An imperative need for global change research in tropical forests. Tree Physiol. 33, 903-912. doi: 10.1093/treephys/tpt064

Conflict of Interest Statement: The authors declare that the research was conducted in the absence of any commercial or financial relationships that could be construed as a potential conflict of interest.

Copyright (c) 2017 Homeier, Báez, Hertel and Leuschner. This is an open-access article distributed under the terms of the Creative Commons Attribution License (CC $B Y)$. The use, distribution or reproduction in other forums is permitted, provided the original author(s) or licensor are credited and that the original publication in this journal is cited, in accordance with accepted academic practice. No use, distribution or reproduction is permitted which does not comply with these terms. 